\title{
MANAGING INFORMATION INTEGRATION IN TODAY'S BUSINESS
}

\author{
Hal Records, PhD, Bryant University, hrecords@bryant.edu \\ Nancy M. Records, MS, MBA, Bryant University, nrecords@bryant.edu \\ Robert Behling, PhD, Arrowrock Industries, behlingr@ hotmail.com
}

\begin{abstract}
Business information is often poorly integrated, dominated by complex and outdated legacy systems and systems that may not have the capability to access and manage external information resources. Enterprise Resource Planning (ERP) systems have been introduced to address some of the integration issues, but they are complex and challenging to successfully implement. Information integration software goes beyond ERP to include managing both internal and external information resources.
\end{abstract}

A study was conducted to investigate the degree of information integration as related to industry and company size and to determine whether the degree of information integration impacts managers' strategic and operational value perceptions. It was found that deployment of information integration is highly polarized between firms regardless of industry sector or firm size, that managers who have access to integrated information perceive it as having high strategic and operational value, that mid sized firms appear to have the highest ambiguity about information integration, and that portals appear to be an integration vehicle of choice for small and mid size companies.

Keywords: Data Integration, Data Aggregation, Business Process Reporting, Enterprise Systems, Internal Data, External Data

\section{INTRODUCTION}

Today's business environment is changing rapidly, and poorly integrated IT systems often slow response to meeting customer's needs. In the past, organizations' systems have been developed and deployed as islands of functionality, often incompatible systems that serve as obstacles to business growth and profitability. In today's competitive environment, responding to customers and market opportunities requires integration between people, processes and information.

A great deal of business information resides in sources outside the traditional organizational databases. Add to this that technology has become the largest component of corporate capital spending, almost $40 \%$ of the total [11]. The problem for today's business management, then, is to identify and deploy systems that provide a means to tap into these outside sources. The web is an obvious example of these outside resources, containing everything from personal blogs to online product catalogs. During the next few years, web services are sure to play a vital role in defining enterprise IT architecture. There are numerous other external information sources as well, including commercial databases, government data resources and trade association reports. While access to much of this information is routine for large corporations with a skilled IT staff, many organizations have limited technical staff and must struggle with the complexity of the technology and the ever changing information landscape.

For the past thirty years, business information processing for organizations of all sizes has been dominated by legacy proprietary systems, often defined by work group or functional area. Office workers wanted desktop processing capabilities, while manufacturing and distribution had very different information requirements. The problem is that many of the proprietary systems installed to meet the unique information needs and currently in place do not interoperate with each other and/or outside systems. As business information requirements become more sophisticated, these systems struggle to function effectively within the enterprise infrastructure. An overriding problem is that maintaining standards has not been foremost in systems development efforts in the past, and system customization has taken precedence over strict adherence to standards. This has left organizations with legacy systems that have little or no documentation, are designed to meet specific needs that may no longer be appropriate, and are usually not scalable to meet today's business reporting requirements. A recent and very serious concern is the inability of organizations to manage their information and data management systems to comply with the Sarbanes-Oxley reporting requirements [9]. 


\section{The California Public Utilities Commission Integrates Energy}

\section{Efficiency Programs Workflow}

The California Public Utilities Commission regulates privately owned electric, telecommunications, water and transportation companies, overseeing implementation of 185 state and local programs related to improving energy efficiency. Program managers submit thousands of data items, reports and other communications related to their energy efficiency improvement efforts. When reporting frequency was increased from quarterly to monthly, program implementers found it difficult to manage documentation, reporting and communication. Especially troubling was data exchange using e-mails with large documents attached. Program implementers needed better integration to manage and track their submissions, requests for additional documentation, and approval status.

The solution was found utilizing groupware and other information integration software to create a flexible and secure workflow process through automating data gathering, reporting, approval, and monitoring processes for all submissions from the 185 programs. The integration system that has been implemented is designed to capture, process, and deliver data and documents, and includes built in authorization capabilities to trigger activities such as receipt notices as well as restrict access and viewing of specific status notes and comments to authorized individuals and agencies. This has led to business processes and information flow being better organized, highly automated, and available through web interfaces. With the ability to more effectively track and monitor progress of the various Energy Efficiency programs, applications and activities, errors are reduced and management can be more responsive to program needs. The net result is through information integration Commission decision-making and overall performance is improved.

Adapted from: www.captasris.com/cms_resources/pdfs/case_studies/captaris_workflow/WF_CPUC_CStudy_1204.pdf

Figure 1. California PUC Information Integration Case

There are numerous examples of organizations integrating their information capture, storage and reporting activities. One organization that describes this particularly well is the California PUC (Fig. 1).

Also, in addition to the standards and scalability issues, management must contend with a myriad of software licenses, upgrade fees, integration of technologies and connectivity issues [8]. The days of stand alone applications are over, and management is seeing that improving IT responsiveness through integration can lead to improved business success [6].

During the 1990s deployment of Enterprise Resource Planning (ERP) systems was seen as a means to reengineering legacy systems and bring alignment to business software applications. The ERP system replaces a tangle of complex and often obsolete applications and can be thought of as the information backbone of the organization reaching into all areas of business. Unfortunately, ERP was quickly shown to be a very challenging system to deploy, with more horror stories than successes. The complexity of the software, unrealistic expectations, lack of proper planning, shortage of competent staff, the training necessary for the technical and user staff, the cost of maintenance, and the increased hardware support all contribute to making ERP a very challenging and expensive software solution. It is important to note that the failures are usually not for technical reasons, these systems often fail because the enterprise rejects the ERP implementation. Forcing the ERP system to match existing business practices requires heavy customization, which will come back to haunt the organization when version updates are supplied by the ERP software vendor. The more acceptable solution is to change the organization to meet the requirements of the ERP software [4]. Organizational change is never easy, and when it is imposed by software that is perceived as doing the task less effectively than the current approach, it is often rejected by employees. The challenges are significantly increased for small business managers working on tight budgets with limited IT staff skills and support. The conclusion, then, is that ERP is not the silver bullet to address the changing information needs in most business organizations. Even so, CRM [2] projects that the ERP market will grow to almost $\$ 65$ billion annual sales by 2009 .

\section{Information Technology Integration}

A recent survey of IT decision makers reveals a wide range of perceived reasons for IT infrastructure modernization, including: enhancing security; improving service levels; driving down IT capital costs; reducing risks; keeping ahead of competition; and bringing about business transformation [1]. These are not new goals, but what may be new is the perception that IT will provide the means to achieve them. Looking at technology as a company's primary strategic investment towards achieving its business goals is successful only if the technology investments are across processes, applications and infrastructure [5]. While the survey was of large business, the results apply to small business as well. With the globalization of business and the increased competition, no business can stand on traditional 
practices and feel secure in the future. New ideas such as data warehousing provide subject-oriented, integrated, time variant data as input to the decision making process [3].

A key to information integration is content management, which can be defined as enabling and controlling the creation, organization, usage, delivery, sharing, storage and final disposition of digital business information in all formats. There are three phases of content management:

- Creation and capture of content in digital format.

- Management of content to provide storage, archiving, search and access capabilities.

- Delivery in the appropriate form to the appropriate individual.

Content management will be particularly important to small businesses as the trend towards virtual offices, mergers and cost reduction impact organizations and blogging and social networking become accepted business tools [7].

IT integration activities are designed to link small and large processes within the organization and to aid in the management of critical processes, while eliminating duplicate recording, storage and reporting [10]. If we follow the large business model, the organization should begin with a strategic plan describing their short and long term objectives and goals, followed by operational initiatives to achieve these objectives and goals. These same activities are appropriate for the management of small business IT, and the authors conducted a survey to identify the degree of integration and the impact of information integration in the management of business organizations.

\section{Study Design and Population}

The questionnaire consisted of three parts: 1) Demographics of the respondents' companies/organizations, 2) IT infrastructure and overall management and strategy of the respondents' organization, and 3) Specific information related to the availability and use of integrated information. The survey population was MBA students enrolled in a Northeast university. The total number of respondents was 103, representing 72 companies. The three hypotheses of the study follow: H1: The degree of information integration does not vary by industry; $\mathrm{H} 2$ : The degree of information integration does not vary by company size; H3: The degree of information integration does impact strategic and operational value perceptions, and hence use, by managers.

In order to test the hypotheses, the survey examined information integration as a function of industry type (manufacturing, services, and other) and company size. The number and breadth of major automated systems used by any given business was used as a measure of available information integration, and manager perceptions about the availability, usability, and effectiveness of these systems was used as a measure of the strategic and operational impact of information integration.

\section{Findings}

Hypothesis $\mathrm{H} 1$ proved to be true. The degree of information integration does not vary by industry. As shown in Figure 2, Manufacturing, Service and Other (based on approximately $7 \%$ of the total sample and largely reflecting government organizations) industries demonstrated a very well defined pattern, having approximately $40 \%$ of responses indicating a low level of integration, $10 \%$ medium integration and $50 \%$ high integration. This indicates that firms are largely polarized as being either not into integration, or seriously into it, with very few firms in the middle, regardless of industry sector.

Hypothesis $\mathrm{H} 2$ proved to be false. The degree of information integration does vary by company size. Although the well defined pattern of firms being polarized holds true, there appear to be differences in the level of data integration by firms of varying size. As shown in Figure 3, mid sized firms of 101 to 500 employees were most likely to have the lowest degree of data integration, and large size firms of 500 or more employees were likely to have the highest degree of integration. It is interesting to note that the smallest firms of 1 to 100 employees were in the middle. This may be due in part to the nature of small business, which causes management to take a holistic view of operations and therefore to recognize the need for information integration.

Hypothesis H3 was true. The degree of information integration did impact strategic and operational value perceptions, and hence use, by managers. As shown in Figure 4, value perceptions tracked very closely with the availability of information integration. Hence, when ERPs and other data integration systems were available, managers recognized their value and used them accordingly. 


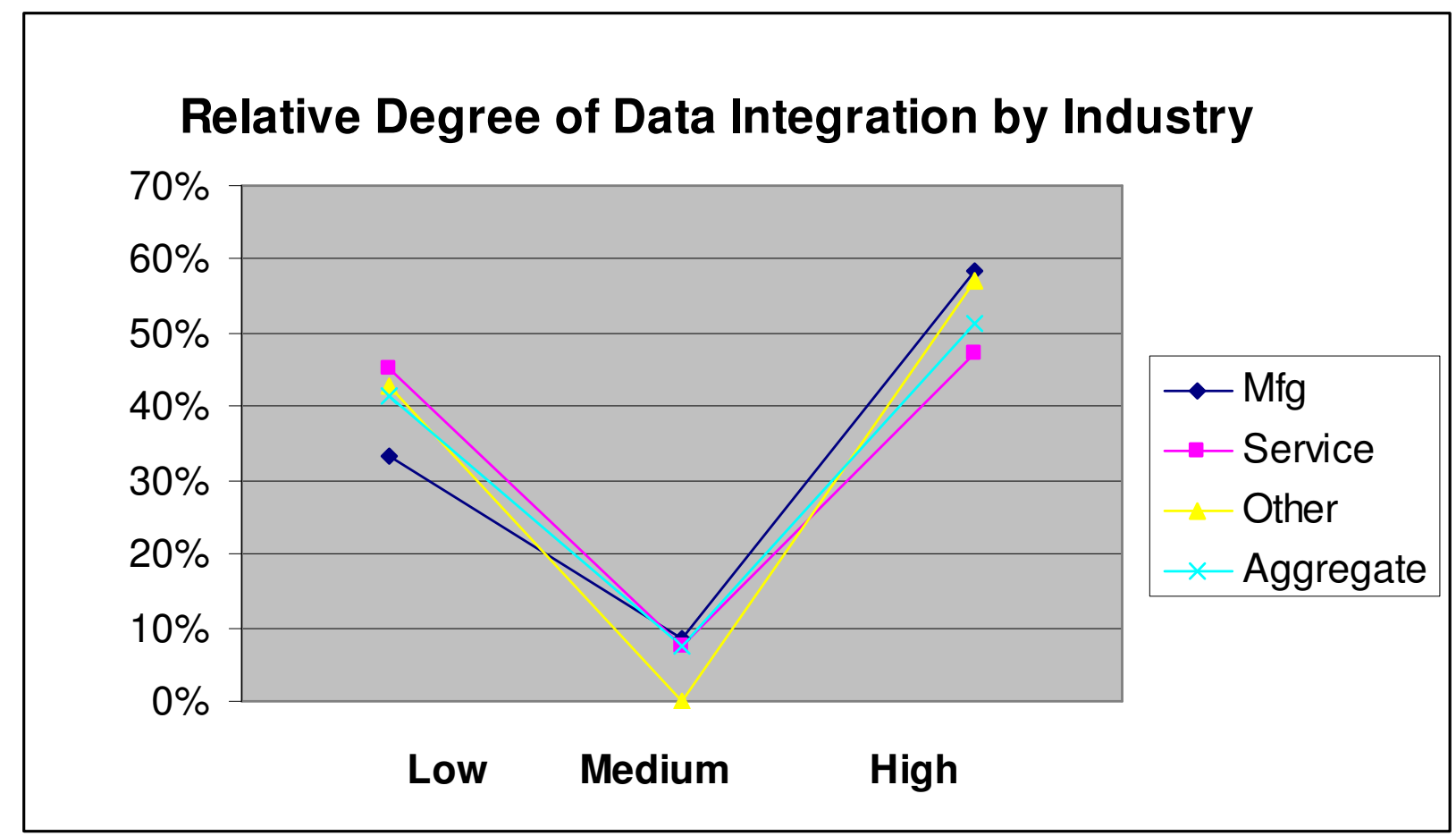

Figure 2. Relative Degree of Data Integration by Industry

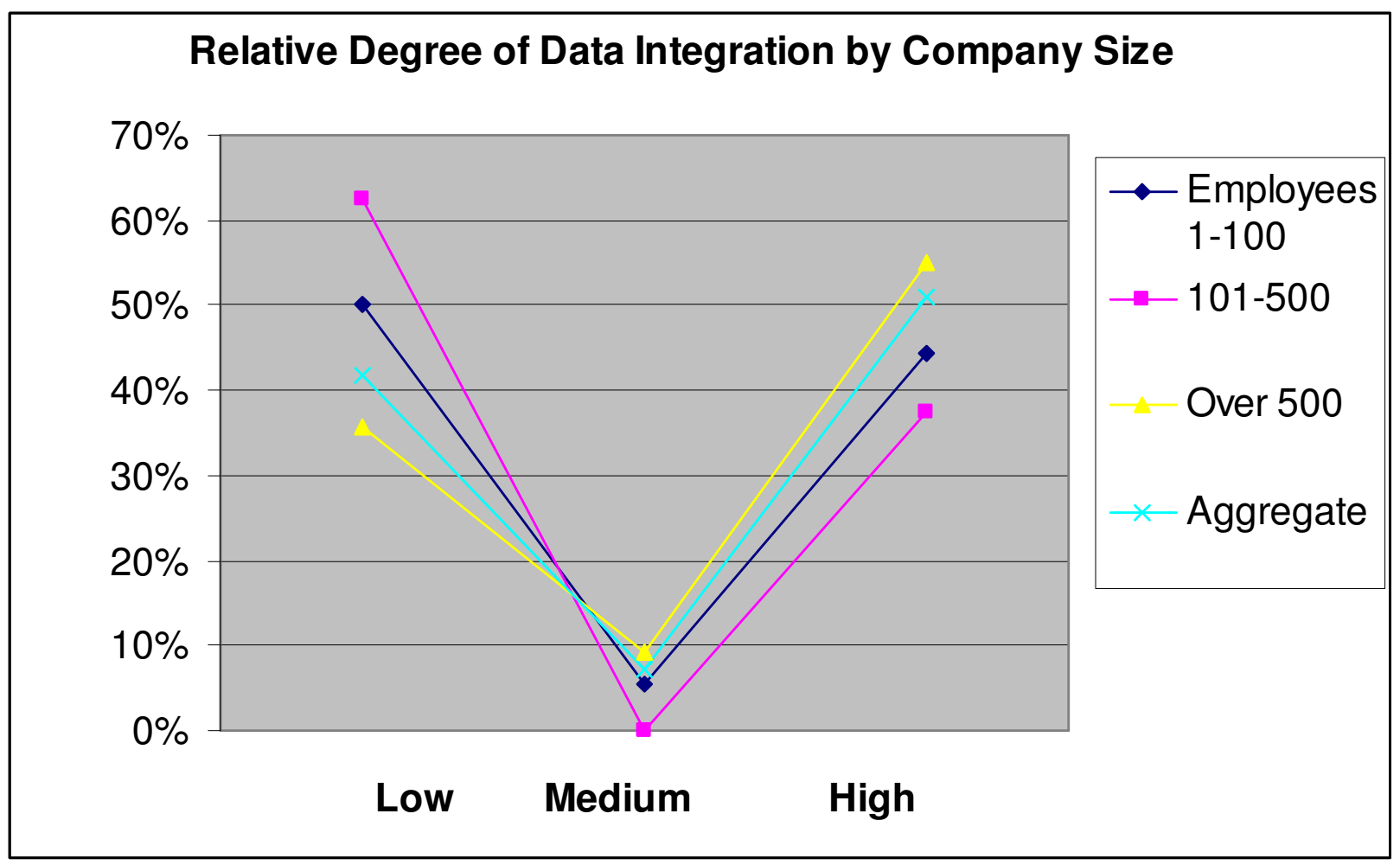

Figure 3. Relative Degree of Data Integration by Company Size 


\section{Relationship of the Degree of Information Integration to Strategic and Operational Values of Managers}

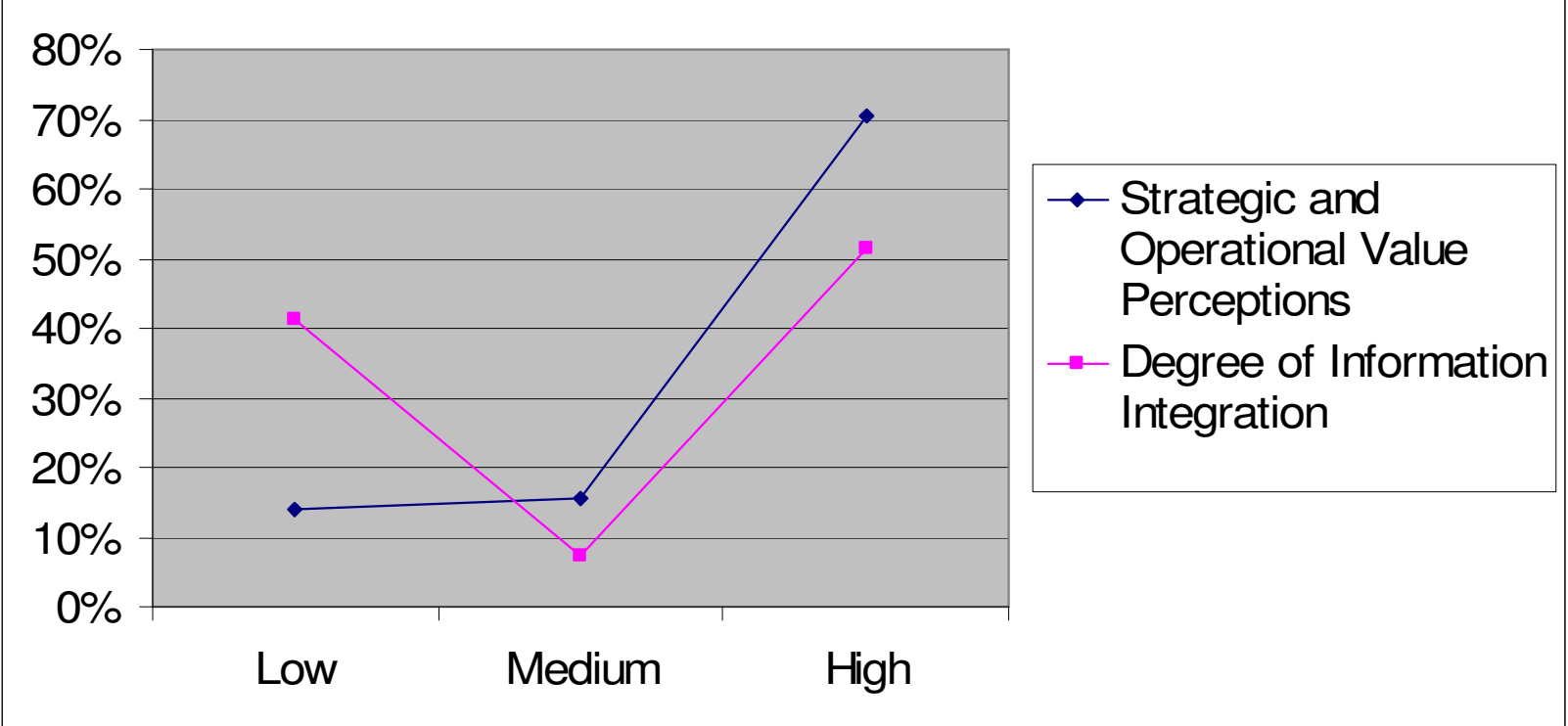

Figure 4. Relationship of the Degree of Information Integration to Strategic and Operational Values of Managers

\section{CONCLUSION AND IMPLICATIONS}

Deployment of information integration is highly polarized between firms regardless of industry sector or firm size, with firms being either seriously into, or not into integration. Managers who have access to integrated information perceive it as having high strategic and operational value. Mid sized firms appear to have the highest ambiguity about information integration and may consequently be a good target market for providers. Portals appear to be an integration vehicle of choice for small and mid size companies, perhaps because of cost considerations. Areas for further research include the impact of Sarbanes-Oxley on integration, value perceptions of information integration as related to management level, and a comparison of portals as a common denominator across legacy systems and as a potentially less expensive substitute for ERP systems.

\section{REFERENCES}

1. An Infrastructure Imperative. (2005). Business Week, September 26, 52-53.

2. \$17 Billion Expected Future Growth in Enterprise Applications Market. (Friday, 14
October, 2005). CRM Today. Available online at http://www.crm2day.com/news/crm/115933.php, $1-3$.

3. Gray, P. (2006). Manager's Guide to Making Decisions about Information Systems, Hoboken, NJ: John Wiley \& Sons, Inc.

4. Gunson, J. \& J. de Blasis. (2002) Implementing ERP in multinational companies: Their effects on the organization and individuals at work. CRM Today. Available online at http://www.crm2day.com/library/EpFlAAlukuE RJZrfaE.php, 1-20.

5. IBM1. A New Approach to Driving Business Value. (2005). IBM. Available online at: http://www-

1.ibm.com/businesscenter/smb/us/en/contenttem plate/gcl_xmlid/36332/nav_id/resources, 1-4.

6. IBM2. Business Integration to Help Gain Competitive Advantage, (2005).IBM. Available online at: http://whitepaper.sc/magazine.com/cpmsd/magaz ine/search/viewabstract/77931/indes.jsp, 2.

7. Levy, M. (2005) Ten trends for 2005. Business Strategy for Software Executives: SandHill.com. Available online 
www.sandhill.com/opinion/editorial.php?id=17, 1-6.

8. Loiacono, J. (2005) Tomorrow's business model today. Business Strategy for Software Executives: SandHill.com. Available online at http://www.sandhill.com/opinion/editorial.php?i $\mathrm{d}=43,1-5$.

9. Rapoport, M. (February 21, 2006). Financial stars urge regulators to not dilute SarbanesOxley, Wall Street Journal, C3.
10. Romney , J \& Steinbart, J. (2006). Accounting Information Systems, (10 ${ }^{\text {th }}$ ed. $)$, Upper Saddle River, NJ: Prentice Hall.

11. Sherlund, R. (2005). Software's new economic drivers. Business Strategy for Software Executives: SandHill.com. Available online at http://www.sandhill.com/opionion/editorial.php? $\mathrm{id}=48,1-8$. 